O eixo e a roda, Belo Horizonte, v.25, n.1, p. 37-60, 2016

\title{
Clarice Lispector sob a ótica da imprensa norte-americana: o caso do The New York Times
}

\section{Clarice Lispector from the perspective of the American press: the case of The New York Times}

Vanessa Lopes Lourenço Hanes

Universidade Federal Fluminense (UFF) / CNPq, Rio de Janeiro / Brasil vanessahanes@gmail.com

Andréia Guerini

Universidade Federal de Santa Catarina (UFSC) / CNPq, Florianópolis / Brasil andreia.guerini@gmail.com

Resumo: O objetivo do presente artigo é verificar, por meio de um tipo de aparato epitextual como e quando se dá a presença de Clarice Lispector na imprensa norte-americana, a partir da análise de artigos publicados no jornal The New York Times, disponível integralmente em formato eletrônico. O método utilizado para a análise dos dados foi a compilação das informações primordiais em um quadro subdividido em data de publicação, seção do jornal em que o artigo se insere, autor, título e resumo do conteúdo. Os resultados encontrados indicam que a presença de Clarice Lispector naquele jornal se dá desde outubro de 1964, e não apenas nas seções dedicadas à literatura, mas também naquelas voltadas a outros âmbitos, como música e cinema. Da análise dos dados, concluiu-se que Clarice Lispector foi, desde o princípio de suas aparições no jornal estudado, apresentada ao leitorado norte-americano como uma 
autora canonizada, e que sua presença cresceu mais recentemente na mídia norte-americana graças principalmente ao trabalho de seu editor e biógrafo Benjamin Moser.

Palavras-chave: Clarice Lispector; The New York Times; Estudos da Recepção; Estudos da Tradução.

Abstract: This article presents a diachronic epitextual analysis of Clarice Lispector in The New York Times online database. Basic information from each related article was compiled according to the following categories: date of publication, section, author, title and a summary of the content. The findings indicate that Lispector, with varying frequency, has been a topic since October 1964, not only in the literature, but in the music and cinema sections as well. The analysis showed that she was introduced to American readers from the beginning as a canonized author, and also that her presence in the US media has been on the rise lately due principally to Benjamin Moser, who has produced a high-profile biography and an English volume of her stories.

Keywords: Clarice Lispector; The New York Times; Reception Studies; Translation Studies.

Recebido em 28 de fevereiro de 2016.

Aprovado em 30 de maio de 2016.

Clarice Lispector ocupou e ainda ocupa, como se sabe, uma posição privilegiada no polissistema literário nacional. ${ }^{1}$ Parte do seu sucesso se deveu ao movimento feminista, mas principalmente à força da sua narrativa, que é caracterizada, por exemplo, por Luciana Stegagno Picchio (1997, p. 610), como uma forma de "escritura grau-zero". 2

\footnotetext{
${ }^{1}$ Sobre a teoria dos polissistemas, ver EVEN-ZOHAR, 1990.

2 Stegagno Picchio define a prosa de Clarice Lispector como uma "escritura grau-zero" em oposição à escrita "expressionista, barroca” de Guimarães Rosa, e afirma que o que os aproxima "é a pesquisa da linguagem, do modo narrativo, mais do que da história narrada” (PICCHIO, 1997, p. 610).
} 
Justamente pela força narrativa de Clarice e por sua presença no cenário nacional, nas últimas décadas muito se tem debatido nos círculos acadêmicos brasileiros e até mesmo internacionais sobre diferentes aspectos da divulgação e da recepção das obras de Clarice Lispector. ${ }^{3}$

Reguera (2006, p. 31-32) apresenta um sucinto panorama dos vários parâmetros através dos quais os escritos de Lispector têm sido abordados. São eles:

a) a posição da crítica em geral, que, embasada por concepções distintas de texto e de gêneros literários, ora elogia, ora repudia as suas obras $[\ldots]$

b) os estudos críticos, uma vertente acadêmica especializada no parâmetro anterior que, além de se firmarem como representantes de uma abordagem crítico-analítica das obras literárias, propiciaram o surgimento e a consequente divulgação de uma variedade de ensaios, sobretudo a respeito de suas produções;

c) o público leitor, que, especialmente no final dos anos 1960 e na década de 1970, intensificou a aclamação de seus livros, fomentando o processo de "santificação" da autora e a decorrente canonização de parte de sua produção;

d) os divulgadores da produção clariciana, em especial as editoras que, na maioria dos casos, abordaram a sua ficção, em meio às influências do mercado editorial, como um objeto comercial $[\ldots]$;

e) e, por fim, a própria posição de Clarice Lispector, ao longo de trinta e cinco anos de trabalho, em relação a essas instâncias de recepção e divulgação de sua obra. (REGUERA, 2006, p. 31-32)

Essa amplidão de possibilidades já exploradas no estudo do universo clariciano serve por si só para demonstrar o papel de singular

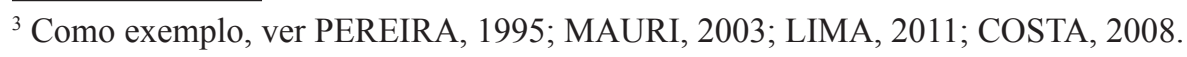


importância ocupado por Lispector no cenário literário e acadêmico. Sua posição privilegiada no cânone brasileiro é ecoada por diversos estudiosos e, como afirma Lisboa (2008), a ficção de autoria feminina no Brasil após a década de 1970 tem em Clarice Lispector sua referência mais importante.

Um dos aspectos da trajetória de Lispector no Brasil, conforme já indicado por Reguera (2006), foi sua aclamação pela crítica literária e, concomitantemente, pelo público leitor nacional, que já nas décadas de 1960 e 1970 consideravam Lispector um dos grandes nomes da literatura brasileira. Clarice Lispector foi, portanto, bem-sucedida e bem recebida entre os intelectuais, mas também entre o público de literatura em geral. Porém, tal trajetória, à primeira vista, parece não ter se repetido do mesmo modo no exterior.

Nos Estados Unidos, nação que serve como cenário para o desenvolvimento do presente artigo, Lispector aparentemente percorreu um caminho um pouco diferente: embora existam já há algumas décadas traduções dos escritos de Clarice Lispector e publicações sobre eles disponíveis naquele país, como os livros de Cixous (1990) e de Barbosa (1997), a divulgação do nome dessa autora em território norte-americano parece ter se dado por muito tempo somente em um âmbito quase que exclusivamente acadêmico. ${ }^{4}$ As obras aqui mencionadas, por exemplo, foram lançadas por editoras universitárias, a saber, a University of Minnesota Press, de Minneapolis, e a University Press of the South, de New Orleans, respectivamente.

No jornal The New York Times, selecionado como corpus do presente estudo conforme será esclarecido posteriormente, em um artigo publicado em 12 de agosto de 2009, o crítico literário Dwight Garner se refere a Lispector como uma autora pouco conhecida nos Estados Unidos, adicionando, no entanto, que em território brasileiro Clarice Lispector é extremamente notória, parte do que chama de "realeza literária" (GARNER, 2009).

Diante desses fatos, e por entender que a circulação de um texto em determinada cultura nunca é autônoma, como bem elucida Gentzler (1998), surgiu o interesse de investigar mais a fundo, e de maneira sistemática, como se dá a presença de Clarice Lispector em um âmbito cultural mais amplo dos Estados Unidos: seria possível encontrar

\footnotetext{
${ }^{4}$ Esse fenômeno também ocorre com outros escritores e em outros contextos geográficos. Machado de Assis é um bom exemplo disso.
} 
referências à sua obra em veículos de comunicação de massa, voltados ao público leitor norte-americano em geral? Caso a resposta fosse positiva, desde qual data essa presença seria notada? Seria possível perceber diferenças sincrônicas e diacrônicas?

Devido às limitações de um artigo, decidiu-se que, a princípio, a investigação da temática proposta precisaria ser empreendida através de um estudo de caso, tendo como objeto de análise um só veículo de comunicação de massa norte-americano de grande vulto. E, na busca pelo corpus mais adequado dentre as muitas opções possíveis, o jornal The New York Times (de agora em diante denominado NYT) foi eleito como aquela que melhor serviria para a realização do presente estudo. A disponibilização de seu conteúdo integral online foi determinante para tal escolha.

Além de sua disponibilização online, a escolha do NYT como objeto de análise se deu devido à sua importância no cenário norteamericano e até mesmo mundial. Desde a sua fundação, em 18 de setembro de 1851, esse jornal já recebeu 117 prêmios Pulitzer, mais do que qualquer outro veículo de comunicação. A Encyclopaedia britannica o classifica como um dos maiores jornais do mundo em termos de excelência editorial, ressaltando o seu compromisso com o relato de notícias sem lançar mão de sensacionalismo (THE NEW..., 2015). E, talvez por conta da confiabilidade que tem inspirado há mais de um século em seus leitores, o alcance do NYT é bastante amplo em termos numéricos. De acordo com um levantamento da Associated Press, possivelmente a mais antiga agência de notícias norte-americana, considerando-se o acesso via dispositivos eletrônicos como celulares, tablets e computadores, bem como a venda impressa, o NYT é o segundo jornal de maior circulação diária nos Estados Unidos, ficando atrás somente do The Wall Street Journal, uma publicação com enfoque no mercado financeiro e no mundo dos negócios como um todo, cujo perfil é bastante diferente daquele do NYT (ver TOP..., [s.d.]).

Dada a importância do $N Y T$, o presente artigo tem como objetivo geral investigar a representatividade e a representação de Clarice Lispector na imprensa norte-americana através de um estudo de caso do conteúdo desse jornal disponibilizado em seu website. Para o alcance desse objetivo, a metodologia adotada foi a consulta do acervo total do NYT através da ferramenta de busca fornecida na própria página do jornal. Foi realizada uma busca exata por Clarice Lispector, a qual resultou em 48 ocorrências. 


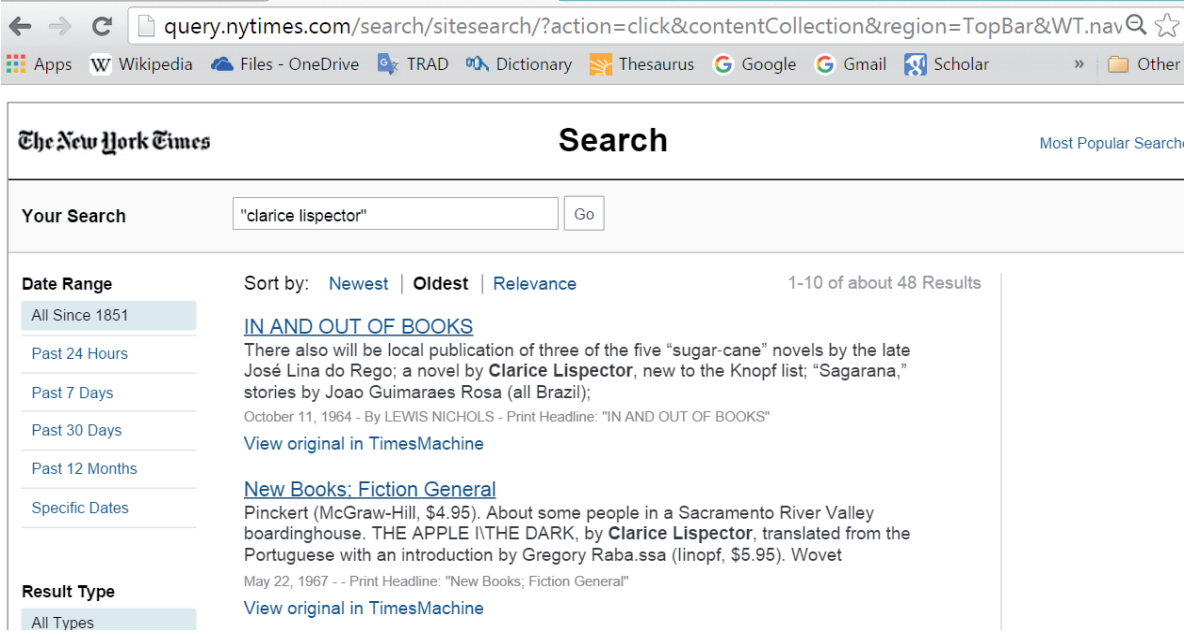

FIGURA 1: Imagem da primeira página de resultados da busca por Clarice Lispector no website do NYT.

O próximo passo metodológico foi o desenvolvimento de um sistema de catalogação dos resultados encontrados que facilitasse a sua compreensão e posterior análise. Assim sendo, o modelo de quadro abaixo foi utilizado para ajudar na visualização da totalidade dos dados.

\section{QUADRO 1}

Modelo de quadro utilizado para compilação dos dados sobre Clarice Lispector encontrados no website do jornal The New York Times

\begin{tabular}{l|l|l|l|l}
\hline DATA & SEÇÃO & AUTOR & TÍTULO & RESUMO \\
\hline
\end{tabular}

No quadro representado pelo modelo acima, data se refere à data de publicação do artigo, seção se refere à subdivisão do jornal na qual o artigo foi publicado, autor se refere ao nome do autor do texto publicado, e resumo consiste em uma breve descrição do conteúdo de cada notícia, ou seja, em que contexto o nome de Lispector é mencionado. Optouse por não apresentar a totalidade dos dados encontrados no corpo do 
presente artigo devido à extensão final do quadro, com nove páginas e quase três mil palavras. Em lugar disso, os resultados foram condensados e os pontos relevantes serão apresentados a seguir. ${ }^{5}$

Conforme já mencionado, as buscas em todo o conteúdo já publicado pelo NYT resultaram em 48 ocorrências para a combinação exata Clarice Lispector. E, ao considerar em maior detalhe cada uma das categorias inseridas no quadro de compilação dos dados, algumas informações surpreendentes foram encontradas e podem ajudar a melhor compreender a inserção dessa importante escritora no sistema cultural norte-americano.

Com relação à data de publicação das notícias catalogadas, a amplitude diacrônica se estendeu de 17 de outubro de 1964 até 10 de janeiro de 2016, demonstrando que Lispector já estava presente na mídia norte-americana nos anos 1960, mais de uma década antes de sua morte, porém vinte anos após a publicação de seu primeiro livro (Perto do coração selvagem). Foram encontradas ainda outras duas ocorrências naquela década, do ano de 1967. Em sua primeira aparição no NYT, em artigo de 1964, o nome de Clarice Lispector é mencionado de passagem, ao lado de outros nomes do cânone literário nacional, a saber, José Lins do Rego e João Guimarães Rosa, devido à intenção de publicação de um dos romances claricianos por parte da editora Knopf. O título do livro em questão não é citado, já que o enfoque principal da notícia é a editora Knopf e sua busca por novos textos latino-americanos (ver NICHOLS, 1964). Com relação às duas aparições de Lispector em 1967, a mais antiga, do mês de maio, trata-se de notícia da publicação da primeira tradução de uma obra da autora em língua inglesa, The apple in the dark (ver NEW..., 1967). Já a outra, do mês de setembro, reflexo da publicação de sua primeira obra nos Estados Unidos, é a primeira referência mais detalhada a Lispector: o artigo em questão apresenta a autora de The apple in the dark, até então quase desconhecida do público norte-americano, com uma breve biografia (ver BRYAN, 1967).

Resumidamente, a diacronia da presença de Lispector no NYT se dá conforme apresentado na tabela a seguir:

\footnotetext{
${ }^{5} \mathrm{O}$ quadro com a compilação total dos dados está disponível para envio a quem tenha interesse, bastando solicitá-lo via e-mail.
} 


\section{TABELA 1}

Diacronia da presença de Clarice Lispector no NYT

\begin{tabular}{l|l}
\hline Ano & Número de ocorrências \\
\hline 1964 & 1 \\
1967 & 2 \\
1982 & 1 \\
1983 & 1 \\
1986 & 2 \\
1987 & 2 \\
1988 & 1 \\
1989 & 2 \\
1994 & 1 \\
1996 & 1 \\
1998 & 2 \\
2004 & 2 \\
2009 & 5 \\
2010 & 1 \\
2011 & 1 \\
2012 & 1 \\
2013 & 2 \\
2014 & 3 \\
2015 & 15 \\
2016 (até fevereiro) & 2 \\
\hline
\end{tabular}

Através desses números, fica evidente o acentuado aumento de notícias que mencionam o nome de Clarice Lispector após os anos 2000: foram 16 até os anos 2000, e 32 após aquela data. Em porcentagens, o equivalente a $33,33 \%$ e $66,66 \%$, respectivamente. Os dois anos que mais se destacaram foram 2009, pois o nome de Lispector foi citado cinco vezes, e 2015, com 15 ocorrências. Esse fato nos fez investigar o que ocorreu de relevante no universo clariciano naqueles dois anos. E a resposta parece ser relativamente simples: em 2009 foi lançada uma biografia da autora em língua inglesa, intitulada Why this world: a biography of Clarice Lispector, escrita por Benjamin Moser. 
Já em 2015 ocorreu outro evento de grande importância para ampliar a presença de Lispector no cenário norte-americano: o lançamento de uma coletânea de suas obras, denominada The complete stories, editada por Benjamin Moser.

Começou a partir daqui a se delinear uma clara relação entre a presença de Clarice na imprensa norte-americana através do NYT e o trabalho de Benjamin Moser associado à sua obra. A relevância de tal conexão ficou ainda mais clara quando os autores de cada artigo sobre Lispector e o conteúdo desses textos passou a ser considerado, conforme será demonstrado a seguir. ${ }^{6}$

No que se refere à autoria do corpus, 11 dentre os artigos encontrados não apresentam qualquer indicação explícita de nomes. Um deles traz somente a informação de que foi escrito pelos editores. Esses textos sem autoria explícita são de 1967 até 2015, mostrando uma tendência já estabelecida daquele veículo de comunicação. Ao ler o conteúdo dos artigos, no entanto, algumas indicações de autoria podem ser encontradas, como em um texto de dezembro de 2015 intitulado "What's the best book, new or old, you read this year?" (Qual o melhor livro, novo ou antigo, que você leu este ano?), em que durante a leitura fica claro que se trata de um relato das respostas individuais dadas à pergunta que aparece no título pelos 16 colunistas da seção de literatura do NYT

\footnotetext{
${ }^{6}$ Com relação às traduções de Clarice Lispector em língua inglesa, em busca realizada no catálogo disponibilizado online pelo Instituto Moreira Salles (ver CLARICE..., [s.d.]) foram encontrados os seguintes títulos: An apprenticeship or the book of delights (tradução de Uma aprendizagem ou o livro dos prazeres, lançada em 1986); The hour of the star (duas traduções de A hora da estrela, de 1984 e 2011); The stream of life (tradução de Água viva publicada em 1989); The besieged city (tradução de $A$ cidade sitiada, de 1995); Discovering the world e Selected crônicas (traduções de $A$ descoberta do mundo publicadas em 1992 e 1996, respectivamente); Family ties (tradução de Laços de familia publicada em 1984); The foreign legion: stories and chronicles (tradução de Legião estrangeira de 1986); The apple in the dark (tradução de $A$ maçã no escuro de 1967); The passion according to G. H. (A paixão segundo G. H., traduzido em 1977, 1988 e 2012); Near to the wild heart (traduções de Perto do coração selvagem de 1990 e 2012); A breath of life (tradução de Um sopro de vida lançada em 2012); Soulstorm: stories (volume traduzido de 1989 que combina textos dos livros $A$ via crucis do corpo e Onde estivestes de noite); e The complete stories (o volume de traduções de diversos textos organizado por Benjamin Moser em 2015).Maiores informações referentes a tradutores, editoras, etc., podem ser encontradas na lista de referências.
} 
(ver WHAT'S..., 2015). Entre esses colunistas encontra-se Benjamin Moser. Eis aqui a primeira explicação encontrada para o elo existente entre Lispector e o NYT: o seu biografista e editor nos Estados Unidos é também um colaborador frequente do jornal estudado. Na verdade, entre os outros textos nos quais o nome de Clarice Lispector é citado, cuja autoria é declarada, Moser também é responsável, seja sozinho ou em coautoria, por dez deles. Os coautores, porém, variam bastante (só se repetem em dois casos, com duas coautorias entre Moser e Pankaj Mishra e Dana Stevens).

E ainda há mais a ser revelado sobre a relação entre Moser e Lispector no NYT: naqueles textos nos quais não figura como autor, Moser também é citado em diversas ocasiões. No ano de 2009, o mesmo em que sua biografia de Lispector foi lançada, Moser foi alvo de particular destaque, sendo mencionado em três ocasiões no NYT lado a lado com Lispector em textos de outrem, todas as vezes no mês de agosto: Fernanda Eberstadt foi a autora de uma resenha da biografia em questão (ver EBERSTADT, 2009); já Dwight Garner também teceu comentários sobre o mesmo livro em outro artigo (ver GARNER, 2009); e, por fim, Blake Wilson conduziu uma entrevista com Benjamin Moser (ver MOSER, 2009). Anos mais tarde, em fevereiro de 2013, John Williams traz novamente o nome de Moser à tona no NYT para escrever sobre sua intenção de publicar uma biografia de Susan Sontag (ver WILLIAMS, 2013).

Ao se considerar o conteúdo dos textos em que Moser figura como autor e nos quais o nome de Lispector é encontrado, o corpus consultado se desdobra em uma nova descoberta: percebe-se que, em vários casos, Lispector não é o assunto em questão. Uma vez que Moser atua como autor colaborador da coluna de literatura do NYT, em muitas ocorrências o nome de Lispector aparece somente na nota biográfica de Moser que acompanha os seus textos, descrevendo-o como biógrafo de Lispector e como editor de sua obra nos Estados Unidos. Esse foi o caso em 15 das 48 ocorrências analisadas, significando que Lispector é mencionada em caráter secundário, como parte das credenciais do crítico literário Benjamin Moser, em 31,25\% dos casos. ${ }^{7}$

\footnotetext{
${ }^{7}$ Devido ao protagonismo de Moser nos resultados encontrados, convém mencionar alguns dados biográficos. Benjamin Moser é um norte-americano nascido no estado do Texas em 14 de setembro de 1976, porém atualmente reside em Utrecht, nos Países Baixos. Sua formação acadêmica deu-se na área de história. Concluiu sua graduação nos
} 
Vale lembrar que o interesse de Moser por Clarice Lispector começou quando estudava literatura de língua portuguesa. Devido à admiração que os livros de Lispector lhe despertaram, durante um período de cinco anos Moser viajou por vários países significativos na trajetória de vida da autora, realizou 257 entrevistas, adquiriu centenas de livros, e todo esse trabalho resultou na biografia já mencionada no presente artigo. Essa biografia foi muito divulgada e comentada em diferentes tipos de mídia. O website do autor apresenta links para 27 resenhas em diferentes veículos de comunicação de grande vulto, incluindo não só o The New York Times, mas também o Los Angeles Time, o Boston Globe, a American Vogue, e assim por diante. $\mathrm{O}$ fato de sua obra ter sido publicada por uma editora prestigiada como a Oxford University Press também não passou despercebido. Entretanto, embora essa biografia tenha recebido muitas críticas positivas, particularmente no exterior; tenha sido traduzida e publicada em outros países, ${ }^{8}$ e tenha sido um sucesso de vendas editado em diferentes formatos, essa recepção positiva da obra de Moser não é uma unanimidade, em especial em terras brasileiras. Seu trabalho é duramente criticado, por exemplo, por Abdala Júnior (2010), que coloca em xeque até mesmo a sua autenticidade. Ao discorrer sobre Clarice, (lêse Clarice vírgula), a tradução da biografia escrita por Moser, ele afirma:

De fato, Moser recorre, salvo dois ou três textos inéditos aí mencionados, a uma mesma massa documental já analisada pelas biógrafas que o antecederam. São, por exemplo, textos críticos que surgem após a publicação dos romances, correspondência trocada entre Clarice e irmãs e entre Clarice e amigos, entrevistas concedidas por Clarice em vários periódicos, sobretudo no Rio de Janeiro (ABDALA JUNIOR, 2010, p. 287).

Todavia, o mesmo Abdala Júnior (2010, p. 288) reconhece que há aspectos inovadores nos escritos de Moser, particularmente no que se refere à relação entre Lispector e sua ascendência judaica:

Estados Unidos (pela Universidade Brown) e tanto seu mestrado quanto o doutorado foram cursados nos Países Baixos (pela Universidade de Utrecht). Atualmente Moser trabalha como escritor e tradutor, e além de ser colaborador frequente do NYT, também atua como colunista de novos livros na Harper's Magazine.

${ }^{8}$ Até o momento, além de nos Estados Unidos, o livro foi lançado no Reino Unido, em Portugal e no Brasil. 
O elemento diferencial da biografia feita por Moser reside, no entanto, no enfoque voltado para as questões judaicas na vida e obra de Clarice. Informações detalhadas sobre a origem dos conflitos no Leste Europeu, responsáveis pelo movimento migratório da população judaica para outros continentes, como para as Américas, servem de respaldo para a história da própria família judia de Clarice, que precisou sair da Ucrânia para o Brasil. Encontram-se ecos dessa cultura em vários momentos do livro, quando o autor se refere a leituras feitas por Clarice (de Espinosa, por exemplo) e a textos escritos por Clarice (em que procura, sobretudo, estabelecer relações com essa cultura de origem).

Após as necessárias considerações sobre Moser, entretanto, é imperativo voltar a outras menções do nome de Clarice Lispector no NYT. Apesar da grande relevância da associação entre o nome de Moser e o da autora, e da indiscutível contribuição do crítico para que a visibilidade de Lispector nos Estados Unidos aumentasse grandemente, outros colunistas do NYT também trouxeram Lispector à baila em contextos de considerável relevância. Entre esses, Lispector é mencionada no NYT com considerável frequência em um estabelecimento de relações entre sua literatura e diversas outras formas de arte.

Já em 1987, por conta do lançamento nos Estados Unidos de um filme dirigido por Suzana Amaral e adaptado do romance $A$ hora da estrela, de Clarice Lispector, a autora é citada por duas vezes na coluna dedicada à arte cinematográfica. O filme homônimo foi lançado no Brasil em 1985, e foi alvo de considerável destaque no exterior, recebendo prêmios no Festival de Berlim (Urso de Prata para Marcélia Cartaxo, a protagonista) e no Festival de Havana (onde Suzana Amaral foi escolhida melhor diretora), além de também ter se destacado bastante no âmbito do cinema nacional, sagrando-se o grande vencedor do Festival de Brasília em 1985 (recebeu seis prêmios, entre os quais o de melhor filme, melhor ator e melhor atriz). Ao fazer menção à Lispector para que o público norte-americano soubesse que o prestigioso filme derivava de sua obra, o colunista Mervyn Rothstein referiu-se a ela como a principal escritora de prosa latino-americana do século passado (ROTHSTEIN, 1987). Janet Maslin, por sua vez, ao discorrer sobre o filme apresentou uma sucinta biografia de Lispector aos norte-americanos (ver MASLIN, 
1987). Bem mais tarde, no ano de 1998 , um texto de B. Ruby Rich volta a mencionar o filme dirigido por Amaral e, consequentemente, o nome de Clarice Lispector, em um contexto que associa cinema e política (ver RICH, 1998).

No mesmo ano de 1998, Lispector voltou a ser mencionada no NYT na coluna de Artes, dessa vez tendo seu nome associado a um espetáculo de dança chamado Pig, dirigido por Linda Austin. A colunista Jennifer Dunning (1998) explica que o espetáculo é apresentado por sete bailarinas, se divide em três partes, e tem inspiração na obra da brasileira Clarice Lispector. E, já em 2004, o nome de Lispector aparece mais uma vez associado à dança, em um guia de atividades musicais e de dança do NYT. A menção da autora dessa vez se deu por conta de uma apresentação de Pascale Wettstein baseada na obra de Lispector (ver CLASSICAL..., 2004).

Mais recentemente, no ano de 2015, Clarice Lispector foi novamente citada pelo NYT em duas ocasiões. Na primeira delas, no mês de março, Lispector foi mencionada na seção de Cultura em associação com ainda outra forma de arte: a pintura. A pintora R. H. Quaytman afirmou na ocasião, em uma entrevista concedida a Christine Smallwood (2015), que sua mostra mais recente envolveu pesquisas nas obras de diferentes artistas e autores de literatura, entre eles, Clarice Lispector. Smallwood explica que "Quaytman começa com pesquisa; sua mostra mais recente envolveu a investigação de Lygia Clark, Clarice Lispector..." (SMALLWOOD, 2015). ${ }^{9}$

Naquele mesmo ano, o nome de Clarice Lispector pôde ainda ser encontrado na seção do $N Y T$ dedicada à música. Em um texto de autoria de Ben Ratliff (2015), o colunista faz uma associação entre as mudanças recentes no universo da música e a obra clariciana, fazendo menção ao fato de encontrar-se naquele momento lendo as novas traduções de Lispector, recém-publicadas no mercado editorial norte-americano. Ele afirma que se viu, junto a outros leitores, devorando a obra traduzida de Clarice Lispector, a qual "cresceu significativamente esse ano com a publicação de uma coletânea de suas histórias" (RATLIFF, 2015). ${ }^{10}$

\footnotetext{
9 "Quaytman begins with research; her most recent show involved investigations into Lygia Clark, Clarice Lispector..." (Tradução nossa).

10 "[...] enlarged significantly this year by the publication of her collected stories" (Tradução nossa).
} 
Outro aspecto notável e que parece ter grande relevância na tentativa de delinear a representação e a representatividade de Clarice Lispector no NYT é o fato de essa autora ser, por décadas, mencionada de forma sistemática junto a grandes nomes da literatura brasileira e latinoamericana. Com relação aos autores brasileiros, seguem aqueles junto dos quais Lispector foi mencionada pelo NYT: José Lins do Rego, João Guimarães Rosa, Lygia Fagundes Telles (mencionada juntamente com Lispector ainda em 1982 como um dos raros exemplos de autoras latinoamericanas já traduzidas nos Estados Unidos), Machado de Assis, Jorge Amado, Márcio Souza, Carlos Drummond de Andrade, Rubem Fonseca e Nélida Piñon. No que se refere a autores latino-americanos de outros países que não o Brasil, a lista também é vasta e prestigiosa: inclui os nomes de Luisa Valenzuela, Marta Lynch, Elena Poniatowska, Rosario Castellanos, Isabel Allende, Javier Cercas, Carlos Fuentes, Pablo Neruda, Mario Vargas Llosa, Octavio Paz e Jacobo Timerman. Sua associação com tais autores no universo de informações do NYT serve como prova da difusão da visão de Lispector sob uma ótica semelhante à brasileira no tocante à sua posição de autora canonizada.

E essa ênfase no nome de Clarice Lispector enquanto autora de destaque e merecedora de prestígio é vista ainda nos escritos de outros autores do NYT. Por exemplo: em um texto de maio de 2004 no qual apresenta uma resenha do livro Death in Brazil, de Peter Robb, o autor Richard Eder diz se sentir desapontado pois, apesar de o livro em questão discorrer sobre Machado de Assis, Euclides da Cunha e Gilberto Freyre, deixa de fora Clarice Lispector, que para Eder se trata de uma escritora dona de uma arte original e intimamente impressionante, embora ela seja conhecida no exterior principalmente como autora feminista (EDER, 2004). Essa foi, por sinal, a única menção a Lispector no NYT que a associou abertamente ao movimento feminista.

De modo geral pode-se, portanto, concluir que o perfil de Lispector traçado pelo NYT é extremamente positivo e surpreendentemente vasto, estabelecendo-a como autora canonizada e fonte da qual bebem não só outros literatos, mas também artistas das mais diversas áreas. A autora é quase que em $100 \%$ das ocasiões mencionada de forma lisonjeira, sendo que nem mesmo sua aparência física (Clarice Lispector, como é sabido, era uma mulher belíssima) é deixada de lado pelos colunistas: ela é descrita como "sempre glamorosa" em texto de autoria de Sheila Glaser publicado em março de 2011, no qual fala de autores considerados 
pouco lidos nos Estados Unidos (ver GLASER, 2011). Até mesmo quando o insólito de seus escritos é colocado em evidência em uma resenha de suas traduções mais recentes, escrita por Terrence Rafferty em agosto de 2015, Lispector é ao mesmo tempo referida como uma ótima autora, sendo o mesmo insólito exaltado como o ingrediente responsável pela densidade dos escritos claricianos (RAFFERTY, 2015). Ademais, o desconhecimento de quem é Clarice Lispector é, já há algum tempo, mencionado como algo quase vergonhoso para o público leitor norte-americano.

A colunista Suzanne Ruta, ainda em 1989, fez questão de, lançando mão de considerável dose de sarcasmo ao resenhar a tradução de $A$ paixão segundo $G$. H., afirmar que a autora brasileira, que qualifica como talentosa, poderia ser o elo perdido entre os grandes movimentos intelectuais da França moderna, a saber, existencialismo e estruturalismo, e talvez essa seja a explicação para que os franceses a considerem seriamente e os norte-americanos não (RUTA, 1989).

Até mesmo o prestígio de um dos responsáveis por traduzir Lispector é ressaltado no NYT: em um texto de maio de 1988, o tradutor Gregory Rabassa, responsável pela versão de $A$ maçã no escuro, é exaltado por receber o Wheatland Prize, prêmio conferido por notável contribuição com a troca literária internacional. Rabassa traduziu, além de Lispector, outros grandes autores como Jorge Amado e Gabriel Garcia Marquez (MCDOWELL, 1988).

Entretanto, apesar das diversas menções positivas encontradas já a partir da década de 1960 e apresentadas aqui, o apogeu das ocorrências do nome de Clarice Lispector no NYT se deu em novembro de 2015, quando a coletânea de obras suas editada por Benjamin Moser e intitulada The complete stories foi incluída na lista dos 100 livros notáveis de 2015, elaborada pelos editores do NYT (ver 100..., 2015). Essa lista inclui obras de ficção, não-ficção e poesia já resenhadas pelos editores do jornal durante o último ano. E a inclusão dos escritos de Lispector foi, sem dúvida, um dos motivos que alavancaram uma nova onda de popularidade da obra clariciana em terras norte-americanas.

Por fim, em janeiro de 2016, o NYT forneceu uma forte evidência da crescente significância de Clarice Lispector no cenário cultural norte-americano, talvez até como reflexo da sua aparição na lista dos livros notáveis de 2015. Ao escrever sua resenha do livro Fake missed connections, de autoria de Brett Fletcher Lauer, o colunista Benjamin Anastas (2016) cita uma famosa sentença proferida por Lispector: "Tudo 
o que em mim não prestava era o meu tesouro", encontrada no conto "Os desastres de Sofia", parte de sua obra A legião estrangeira (LISPECTOR, 1992, p. 17). Clarice Lispector é citada sem adendos: sem explicações relativas à sua nacionalidade, sem justificativas reconhecidas como necessárias sobre qual a sua importância no cenário literário para que seja citada em uma resenha em um dos maiores veículos de comunicação dos Estados Unidos e do mundo. Talvez essa ocorrência seja a prova de que, devido a diversos fatores, entre eles a contribuição de Moser, o nome de Clarice Lispector tem alcançado uma posição consolidada na cena literária norte-americana.

Como exposto até agora, percebe-se que a presença de Clarice Lispector no NYT é bastante significativa. Para uma breve comparação, uma busca semelhante com o nome de Guimarães Rosa, autor praticamente da mesma geração, e segundo Stegagno Picchio (1997, p. 605) um dos "mais célebres no exterior", resultou em apenas 23 ocorrências no NYT, menos da metade das 48 encontradas para Lispector, demonstrando que, apesar de o cenário literário norte-americano ser ainda bastante fechado para a literatura estrangeira ${ }^{11} \mathrm{e}$, em especial, para a literatura latino-americana, a autora em questão tem sido alvo de menções constantes quando comparada a outros de sua classe, particularmente na última década, o que serve para atestar um provável aumento de sua popularidade naquele país. Ficou ainda evidente que o seu biógrafo e editor Benjamin Moser teve um importante papel nessa recente divulgação da obra clariciana, e pode talvez em grande medida ser responsabilizado pelo que poderia ser chamado de uma revitalização da imagem dos escritos de Lispector nos Estados Unidos.

De modo geral, foi também revelador perceber que Clarice Lispector em toda a sua trajetória nos Estados Unidos foi apresentada ao público como uma autora de alto nível, não só pelos elogios amplamente tecidos a ela enquanto escritora, mas também pela constante associação de seu nome ao de outros grandes literatos brasileiros e latino-americanos. Ademais, as descrições sobre as obras de Lispector consideradas tenderam a ser apresentadas ao público leitor do jornal americano acompanhadas

\footnotetext{
${ }^{11}$ Vale lembrar que Lawrence Venuti é um dos teóricos mais engajados em criticar sistematicamente algumas das práticas do sistema cultural americano em relação à importação e à tradução de textos de outros sistemas, enfatizando que por detrás disso estão as práticas econômicas que determinam o interesse comercial da indústria editorial (VENUTI, 1995).
} 
de explicações, ainda que breves, sobre a posição ocupada por Clarice Lispector no cenário literário brasileiro, enfatizando sua condição de "realeza literária" nos círculos nacionais.

Considerando um aspecto mais básico, porém não menos intrigante, das informações levantadas, um dos elementos que chamou a atenção foi a diacronia das ocorrências: embora ainda em pequeno número, foi surpreendente ver que Lispector já era mencionada no $N Y T$ ainda em vida, na década de 1960. E sua presença, embora bastante tímida numericamente, não desapareceu daquele veículo de comunicação por muitos anos seguidos desde a década de 1980, embora não tenham sido encontradas ocorrências durante a década de 1970.

Com relação às seções do NYT em que o nome de Lispector foi encontrado, ainda que, como já era esperado, a imensa maioria das ocorrências tenha se dado na seção do jornal dedicada à literatura, foi surpreendente perceber que Lispector também figurava em artigos referentes às mais diferentes áreas artísticas, como cinema, música, dança e pintura, demonstrando assim a relevância de sua obra não só enquanto literatura per se, mas também como base para leituras e releituras intersemióticas de seus escritos. ${ }^{12}$

Outro aspecto bastante importante percebido através dos dados analisados refere-se à ênfase dada à postura de Lispector enquanto parte de algumas minorias sociais. Vale ressaltar que tem sido bastante comum encontrar em tempos mais recentes pesquisas acadêmicas associando a figura e os escritos de Lispector aos estudos feministas, e obviamente há grande fundamento para isso, bastando considerar não só as obras, mas também a trajetória pessoal da autora. Entretanto, no NYT não parece haver uma associação marcada entre Clarice Lispector e os movimentos feministas, mas dá-se certa ênfase ao seu pertencimento a outra minoria: o povo judeu. Esse enfoque talvez tenha sido parcialmente impulsionado pela biografia de Moser, mas mesmo nos textos anteriores a essa publicação, parece haver interesse em se dar certo destaque ao fato de Lispector não ser exatamente brasileira, mas sim de ascendência

${ }^{12}$ No Brasil também há uma crescente tendência a estabelecer associações intersemióticas com a obra de Lispector, como visto nos estudos de Siqueira (2008) e Wosniak (2011), tendência percebida ainda em outros campos, como o dos Estudos da Tradução, conforme apontado por Hanes e Guerini em "Clarice Lispector traduzida e tradutora: estado da arte" (2016), inédito. 
judia, mencionando-se repetidamente no NYT (em artigos de 1967, 1987 e 2012) o fato de a autora ter nascido na Ucrânia pós-guerra e não no Brasil. Não se pretende aqui entrar no debate da já conhecida polêmica acerca da forte influência dos judeus na mídia norte-americana como um todo, porém esse achado não pode, por outro lado, ser ignorado.

Embora o objetivo do presente artigo tenha sido elaborar um estudo de caso que possibilitasse verificar como Lispector tem sido apresentada ao leitor norte-americano em geral, as descobertas proporcionadas pela análise dos dados serviram para mostrar que a presença dessa autora no sistema cultural americano é mais intensa e contínua do que inicialmente se supunha. Além disso, os dados indicam possibilidades de novas análises na compreensão da recepção e do perfil de Lispector nos EUA, como compilações de ocorrências do nome de Lispector em outros veículos de comunicação, por exemplo o prestigioso The New Yorker, e ainda outra possibilidade mais abrangente, que seria um estudo comparado entre as principais nações de língua inglesa, a Inglaterra e os Estados Unidos, em busca de possíveis divergências e convergências na representação e representatividade de Clarice Lispector em veículos de comunicação de ambas as nações e no papel que certos epitextos desempenham na divulgação de um autor em um dado sistema cultural.

\section{Referências}

\section{Aporte teórico-crítico}

ABDALA JÚNIOR, Benjamin. Biografia de Clarice, por Benjamin Moser: coincidências e equívocos. Revista Estudos Avançados, São Paulo, v. 24, n. 70, p. 285-292, 2010.

BARBOSA, Maria José Somerlate. Clarice Lispector: spinning the webs of passion. New Orleans: University Press of the South, 1997.

CIXOUS, Hélène. Reading with Clarice Lispector. Minneapolis: University of Minnesota Press, 1990.

CLARICE Lispector. Instituto Moreira Salles, [s.d.]. Disponível em: $<$ http://claricelispectorims.com.br/Books > . Acesso em: 4 jan. 2016.

COSTA, Walter Carlos. A face holandesa de Clarice Lispector. Revista Cerrados, Brasília, UnB, v. 16, n. 24, p. 287-293, 2008. 
EVEN-ZOHAR, Itamar. Polysystem theory. Poetics Today, Durham, v. 11, n. 1, p. 3-26, 1990.

GENTZLER, Edwin. Teorie della traduzione, tendenze contemporanee. Tradução de Maria Teresa Musacchio. Torino: UTET Libreria, 1998.

LIMA, Thereza Cristina de Souza. A tradução e os prazeres vivos de descobrir o mundo de Clarice Lispector: uma análise comparativa de três obras de Clarice Lispector, traduzidas para o inglês, à luz dos Estudos da Tradução Baseados em Corpus. 2011. 228 f. Tese (Doutorado em Estudos Linguísticos) - Instituto de Biociências, Letras e Ciências Exatas, Universidade Estadual Paulista, São José do Rio Preto, 2011. Disponível em: $<$ http://acervodigital.unesp.br/handle/unesp/157370?locale=pt_BR $>$. Acesso em: 3 dez. 2015.

LISBOA, Adriana. Escrever no Brasil depois de Clarice Lispector: armadilhas ficcionais. Journal of Iberian and Latin American Studies, Adelaide, v. 14, n. 2-3, p. 141-145, 2008.

MAURI, Cristina. Um estudo da tradução italiana de Laços de família, de Clarice Lispector, a partir da abordagem em corpora: a construção da introspecção feminina através dos verbos de elocução. 2003. $108 \mathrm{f}$. Dissertação (Mestrado em Estudos Linguísticos) - Faculdade de Letras, Universidade Federal de Minas Gerais, Belo Horizonte, 2003.

MOSER, Benjamin. Clarice,. Tradução de José Geraldo Couto. São Paulo: Cosac Naify, 2009.

MOSER, Benjamin. Why this world: a biography of Clarice Lispector. New York: Oxford University Press, 2009.

PEREIRA, Maria Marta Laus. Aspectos da recepção de Clarice Lispector na França. Anuário de Literatura, Florianópolis, UFSC, v. 3, n. 3, p. 109125, 1995.

PICCHIO, Luciana Stegagno. História da literatura brasileira. Rio de Janeiro: Editora Nova Aguilar, 1997.

REGUERA, Nilze Maria de Azeredo. Clarice Lispector e a encenação da escritura em A via crucis do corpo. São Paulo: Unesp, 2006.

SIQUEIRA, Joelma Santana. À procura de objetos gritantes: um estudo da narrativa de Clarice Lispector. 2008. 239 f. Tese (Doutorado em Literatura Brasileira) - Faculdade de Filosofia, Letras e Ciências Humanas, Universidade de São Paulo, São Paulo, 2008. Disponível em: $<$ www.teses.usp.br/teses/.../TESE_JOELMA_SANTANA_SIQUEIRA. pdf $>$. Acesso em: 3 nov. 2015. 
THE NEW York Times. In: ENCYCLOPAEDIA Britannica, 2015. Disponível em: $<$ http://global.britannica.com/topic/The-New-YorkTimes>. Acesso em: 10 fev. 2016.

TOP 10 Newspapers by circulation: Wall Street Journal leads weekday circulation. Huffington Post, [s.d.]. Disponível em: $<$ http:// www.huffingtonpost.com/2013/05/01/newspaper-circulation-top10_n_3188612.html >. Acesso em: 12 fev. 2016.

VENUTI, Lawrence. A invisibilidade do tradutor. Tradução de Carolina Alfaro. PaLavra, Departamento de Letras, PUC-Rio, v. 3, p. 111-134, 1995.

WOSNIAK, Cristiane. A literatura, a dança e a tradução intersemiótica: quando Clarice dançou. In: ENCONTRO DO GRUPO INTERDISCIPLINAR DE PESQUISA EM ARTES, 4., 2010, Curitiba. Anais... Curitiba: Faculdade de Artes do Paraná, 2011. Disponível em: $<$ http://www.fap.pr.gov.br/arquivos/File/COMUNICACAO_2013/ Publicacoes/GIPA_e_GEPHEO/08-literatura_danca_traducao_ intersemiotica_wosniak.pdf $>$. Acesso em: 30 jan. 2016.

\section{Corpus da pesquisa}

100 notable books of 2015. The New York Times, New York, 27 Nov. 2015. Disponível em: <http://www.nytimes.com/2015/12/06/books/ review/100-notable-books-of-2015.html>. Acesso em: 04 fev. 2016.

ANASTAS, Benjamin. 'Fake missed connections,' by Brett Fletcher Lauer. The New York Times, New York, 8 Jan. 2016. Books. Disponível em: <http://www.nytimes.com/2016/01/10/books/review/fake-missedconnections-by-brett-fletcher-lauer.html? mtrref=query.nytimes. com\&gwh=1C66EA2CFB99FD25F209CF362014B1D7\&gwt=pay>. Acesso em: 16 fev. 2016.

BRYAN, C. D. B. Afraid to be afraid. The New York Times, New York, 3 Sep. 1967. Book Review. Disponível em: <http://query.nytimes.com/ gst/abstract.html?res=9A07E2DD1F3CE63ABC4B53DFBF66838C67 9EDE >. Acesso em: 16 fev. 2016.

CLASSICAL music and dance guide. The New York Times, New York, 7 May 2004. Movies. Disponível em: <http://www.nytimes. com/2004/05/07/movies/classical-music-and-dance-guide.html $>$. Acesso em: 16 fev. 2016. 
DUNNING, Jennifer. A strange little world with a barrel that flirts. The New York Times, New York, 9 Mar. 1998. Dance Review. Disponível em: $<$ http://www.nytimes.com/1998/03/09/arts/dance-review-a-strange-littleworld-with-a-barrel-that-flirts.html>. Acesso em: 16 fev. 2016.

EBERSTADT, Fernanda. Untamed creature. The New York Times, New York, 19 Aug. 2009. Sunday Book Review. Disponível em: $<$ http://www. nytimes.com/2009/08/23/books/review/Eberstadt-t.html?mtrref=query. nytimes.com\&gwh=5E47F7A3E8E29683611CF1146423B162\&gwt=p ay>. Acesso em: 16 fev. 2016.

EDER, Richard. Trekking wildly in Brazil, with history and violence. The New York Times, New York, 18 May 2004. Books of the Times. Disponível em: <http://www.nytimes.com/2004/05/18/books/books-ofthe-times-trekking-wildly-in-brazil-with-history-and-violence.html>. Acesso em: 16 fev. 2016.

GARNER, Dwight. Writer's myth looms as large as the many novels she wrote. The New York Times, New York, 11 Aug. 2009. Books of the Times. Disponível em: <http://www.nytimes.com/2009/08/12/books/12garner. html?_r=0>. Acesso em: 16 fev. 2016.

GLASER, Sheila. Writers no one reads? The New York Times, New York, 2 Mar. 2011. Magazine. Disponível em: $<$ http://6thfloor.blogs.nytimes. com/2011/03/02/writers-no-one-reads/?mtrref=query.nytimes.com\&g $w h=A 27 D 831 B F 76 D B D 3827 C 96 A 7353 B 23 E 9 C \& g w t=$ pay $>$. Acesso em: 16 fev. 2016.

MASLIN, Janet. The screen: 'The hour of the star,' from Brazil. The New York Times, New York, 21 Jan. 1987. Movies. Disponível em: <http:// www.nytimes.com/1987/01/21/movies/the-screen-the-hour-of-the-starfrom-brazil.html?mtrref=query.nytimes.com\&gwh=E5EF23CE8CD792 992F44F283CF7BE6A1\&gwt=pay>. Acesso em: 16 fev. 2016.

MCDOWELL, Edwin. American translator wins award. The New York Times, New York, 8 May 1988. Books. Disponível em: <http://www. nytimes.com/1988/05/08/books/american-translator-wins-award.html>. Acesso em: 16 fev. 2016.

MOSER, Benjamin. Stray questions for: Benjamin Moser. Arts Beat: The Culture at Large, $21 \mathrm{Aug}$. 2009. Blog vinculado à página do The New York Times. Entrevista concedida a Blake Wilson. Disponível em: $<$ http:// artsbeat.blogs.nytimes.com/2009/08/21/stray-questions-for-benjaminmoser/?mtrref=query.nytimes.com\&gwh=111951923AEF41898AA04 3AC2FCB7742\&gwt=pay>. Acesso em: 16 fev. 2016. 
NEW books; fiction general. The New York Times, New York, 22 May 1967. Disponível em: <http://query.nytimes.com/gst/abstract.html?res= 9D02E4D61338E43BBC4A51DFB366838C679EDE>. Acesso em: 16 fev. 2016.

NICHOLS, Lewis. In and out of books. The New York Times, New York, 11 Oct. 1954. Disponível em: <http://www.nytimes.com/1964/10/11/ in-and-out-of-books.html>. Acesso em:

RAFFERTY, Terrence. 'The complete stories,' by Clarice Lispector. The New York Times, New York, 27 Jul. 2015. Book Review. Disponível em: <http://www.nytimes.com/2015/08/02/books/review/the-completestories-by-clarice-lispector.html>. Acesso em: 16 fev. 2016.

RATLIFF, Ben. Musicians redefine long play in 2015. The New York Times, New York, 16 Dec. 2015. Arts. Disponível em: <http://www. nytimes.com/2015/12/20/arts/music/musicians-redefine-long-playin-2015.html>. Acesso em: 16 fev. 2016.

REVIEWS of Why this world. Benjamin Moser, [s.d.]. Disponível em: $<$ http://www.benmoser.com/index2.php?soort=work\&volgorde subnav $=2>$. Acesso em: 20 fev. 2016.

RICH, B. Ruby. Cinema that rolls with the politics. The New York Times, New York, 29 Nov. 1998. Film. Disponível em: <http://www.nytimes. com/1998/11/29/movies/film-cinema-that-rolls-with-the-politics. html?mtrref=query.nytimes.com\&gwh=97D9F2DE108E83F35284527 F53725D7A\&gwt=pay>. Acesso em: 16 fev. 2016.

ROTHSTEIN, Mervyn. Suzana Amaral: her 'hour' has come. The New York Times, New York, 18 Jan. 1987. Movies. Disponível em: <http:// www.nytimes.com/1987/01/18/movies/suzana-amaral-her-hour-hascome.html? mtrref=query.nytimes.com\&gwh=ACF87100A1671BB62 A8B5CC32F143C51\&gwt=pay>. Acesso em: 16 fev. 2016.

RUTA, Suzanne. Everything happens in the maid's room. The New York Times, New York, 8 Jan. 1989. Books. Disponível em: <http://www. nytimes.com/1989/01/08/books/everything-happens-in-the-maid-sroom.html>. Acesso em: 16 fev. 2016.

SMALLWOOD, Christine. The mother-daughter thing. The New York Times, New York, 24 Mar. 2015. Family Affairs. Disponível em: <http:// tmagazine.blogs.nytimes.com/2015/03/24/susan-howe-rh-quaytmanmother-daughter-interview/?mtrref=query.nytimes.com\&gwh=193FE16 B4580917E76A9A50A154F1C5D\&gwt=pay>. Acesso em: 16 fev. 2016. 
THE New York Times, New York, 1851-. Disponível em: <http://www. nytimes.com/>. Acesso em: 01 fev. 2016.

WHAT'S the best book, new or old, you read this year? The New York Times, New York, 7 Dec. 2015. Sunday Book Review. Disponível em: $<$ ww.nytimes.com/2015/12/13/books/review/whats-the-best-book-newor-old-you-read-this-year.html>. Acesso em: 16 fev. 2016.

WILLIAMS, John. Benjamin Moser to write Sontag Biography. Arts Beat: The Culture at Large, 27 Feb. 2013. Blog vinculado à página do The New York Times. Disponível em: <http://artsbeat. blogs.nytimes.com/2013/02/27/benjamin-moser-to-write-sontagbiography/?mtrref=query.nytimes.com\&gwh=C07D43D4511EE9F 16 F142805EA6A6459\&gwt=pay>. Acesso em: 16 fev. 2016.

\section{Obras de Clarice Lispector}

LISPECTOR, Clarice. A breath of life. Tradução de Johnny Lorenz. New York: New Directions, 2012.

LISPECTOR, Clarice. A legião estrangeira. São Paulo: Editora Siciliano, 1992.

LISPECTOR, Clarice. An apprenticeship or the book of delights. Tradução de Richard A. Mazzara e Lorri A. Parris. Austin: University of Texas, 1986.

LISPECTOR, Clarice. Discovering the world. Tradução de Giovanni Pontiero. Manchester: Carcanet, 1992.

LISPECTOR, Clarice. Family ties. Tradução de Giovanni Pontiero. Austin: University of Texas, 1972.

LISPECTOR, Clarice. Near to the wild heart. Tradução de Alison Entrekin. New York: New Directions Paperbook, 2012.

LISPECTOR, Clarice. Near to the wild heart. Tradução de Giovanni Pontiero. New York: New Directions, 1990.

LISPECTOR, Clarice. Selected crônicas. Tradução de Giovanni Pontiero. New York: New Directions, 1996.

LISPECTOR, Clarice. Soulstorm: stories. Tradução de Alexis Levitin. New York: New Directions, 1989. 
LISPECTOR, Clarice. The apple in the dark. Tradução de Gregory Rabassa. New York: Alfred A. Knopf, 1967.

LISPECTOR, Clarice. The besieged city. Tradução de Giovanni Pontiero. Manchester: Carcanet, 1995.

LISPECTOR, Clarice. The complete stories. Editado por Benjamin Moser. Tradução de Katrina Dodson. New York: New Directions, 2015. LISPECTOR, Clarice. The foreign legion: stories and chronicles. Tradução de Giovanni Pontiero. Manchester: Carcanet, 1986.

LISPECTOR, Clarice. The hour of the star. Tradução de Benjamin Moser. New York: New Directions, 2011.

LISPECTOR, Clarice. The hour of the star. Tradução de Giovanni Pontiero. Manchester: Carcanet, 1986.

LISPECTOR, Clarice. The passion according to $G$. $H$. Tradução de Idra Novey. New York: New Directions Paperbook, 2012.

LISPECTOR, Clarice. The passion according to G. H. Tradução de Jack H. Tomlins. New York: Knopf, 1977.

LISPECTOR, Clarice. The passion according to G. H. Tradução de Ronald W. Sousa. Minneapolis: University of Minnesota, 1988.

LISPECTOR, Clarice. The stream of life. Tradução de Elizabeth Lowe e Earl Fitz. Minneapolis: University of Minnesota, 1989. 